\title{
O ESTUDO DAS RELAÇÕES INTERNACIONAIS NO BRASIL: OESTADO DA ARTE ${ }^{1}$
}

\author{
Shiguenoli Miyamoto \\ Universidade Estadual de Campinas
}

\section{RESUMO}

Este artigo faz um balanço do estudo das Relações Internacionais no Brasil em dois momentos: antes de 1978 e depois. No primeiro instante verifica-se um número reduzido de profissionais e instituições voltados para esta temática, enquanto que a partir dos anos oitenta ocorre um incremento apreciável, principalmente com a criação de vários cursos de graduação em Relações Internacionais. O artigo também aponta as dificuldades enfrentadas pela área no País, face à intermitência tanto das instituições de ensino e pesquisa voltadas para o tema, quanto das publicações especializadas.

PALAVRAS-CHAVE: Relações Internacionais; politica externa brasileira; instituições de ensino em Relações Internacionais; periódicos de Relações Internacionais.

\section{INTRODUÇÃO}

Até a metade dos anos setenta, o estudo das Relações Internacionais no Brasil — se comparado às outras áreas tradicionais de investigação, como partidos políticos, sindicalismo, estrutura agrária, movimentos sociais etc. - recebeu pouca atenção, e o meio acadêmico contribuiu de forma muito modesta para o seu desenvolvimento.

Contudo, é óbvio que existe uma quantidade razoável de estudos feitos, entre outros, por juristas, economistas, cientistas sociais, historiadores e jornalistas sobre Relações Internacionais, retratando muitos aspectos sobretudo da política externa brasileira, voltados para a Bacia do Prata e África. Há também depoimentos e livros de memórias de diplomatas e militares (que ao final dos

1 Texto apresentado no 1ํㅡㄹ Congresso Brasileiro de Relações Internacionais, promovido pela Universidade de Brasília e Secretaria de Assuntos Estratégicos, realizado em Brasília, de 24 a 26 de março de 1998. Estou incorporando aqui alguns dos comentários feitos na ocasião por José Flávio Sombra Saraiva e por outros colegas como Eiiti Sato na mesa anterior. Agradeço não só a ambos mas, também, a Antônio Jorge R. da Rocha pelas informações sobre 0 Departamento de Relações Internacionais da UnB. 0 texto, como está ora apresentado, é, contudo, de minha inteira responsabilidade. anos noventa estão se avolumando, tentando, cada um à sua maneira, explicar o seu papel no governo militar pós-64 etc.).

A produção sobre Relações Internacionais e política externa brasileira, inclusive, foi objeto de investigação criteriosa por parte do pessoal acadêmico. Zairo Borges Cheibub, por exemplo, levantou os assuntos publicados em revistas brasileiras de 1930 a 1980 e também mapeou os debates intelectuais juntamente com Maria Regina Soares de Lima. Outro texto desta última, escrito em parceria com Gerson Moura, faz um bom retrospecto bibliográfico sobre esta área de estudos no País. Os professores Amado Luiz Cervo e Clodoaldo Bueno, por sua vez, analisaram praticamente toda a produção existente sobre a política exterior brasileira, em obra de grande fôlego, e de fundamental importância para os interessados no assunto (cf. CHEIBUB, 1981; CHEIBUB e LIMA, 1983; LIMA e MOURA, 1982; CERVO, 1992).

Como se pode constatar por estes estudos, o interesse nas décadas anteriores - principalmente nos anos setenta - esteve basicamente centrado no que se passava na Bacia do Prata. A perspectiva tanto brasileira quanto argentina se resumia, em grande parte, em denunciar de um lado o papel pouco amistoso que cada um estaria jogando em detrimento de seu vizinho; e, de outro, na contestação simultânea e recíproca de tais denúncias. A 
produção mais representativa desses dois países, em termos numéricos, se referia a elucubrações feitas por — ou ligados a - militares não só da ativa mas inclusive da reserva, veiculadas em grande parte em publicações por eles mesmos criadas.

No Brasil, o caráter dessa produção militar, às vezes também diplomática, sempre foi mais de cunho geopolítico, fazendo projeções sobre o "Brasil Potência" ou a respeito do papel desempenhado pelas fronteiras na história nacional. Posturas como essa podem ser observadas em dois autores muito citados regionalmente a partir dos anos setenta: o general Carlos de Meira Mattos e o ex-embaixador Álvaro Teixeira Soares (cf. MEIRA MATTOS, 1975; SOARES, 1973). Ao lado de Mário Travassos, Golbery do Couto e Silva e de Therezinha de Castro, aqueles dois primeiros se converteram em alvo favorito, fundamentalmente dos argentinos - e mesmo de brasileiros - que viam neles os influenciadores das políticas nacionais, elaboradas pelo Itamaraty e pela caserna (cf. TRAVASSOS, 1945; COUTO E SILVA, 1967 e CASTRO, 1976; v., também, SCHILLING, 1981). Isto pode ser verificado através da revista mais influente do período denominada Estratégia, cujo diretor era o general de reserva Juan Enrique Guglialmelli, tendo, entre outros, colaboradores como Carlos Mastrorilli e Oscar Camilión.

As numerosas denúncias contra o Brasil eram feitas não só naquela revista, mas também por intermédio de dezenas de livros e periódicos preocupados quase exclusivamente em mostrar o Brasil como País imperialista, logo inimigo que deveria ser combatido a qualquer custo.

Sendo tradicionais rivais que movimentaram a história da Bacia do Prata, Brasil e Argentina permanentemente estiveram no centro das atenções regionais, convertendo-se, portanto, em um dos pontos prioritários analisados pelos cidadãos de ambos os Países. Aliás, não só destes, mas também dos vizinhos diretamente interessados, como o Uruguai, o Paraguai, a Bolívia, e, de maneira mais distante, pelo Chile e Peru.

O interesse no relacionamento destes dois Países foi sempre muito acentuado, porque qualquer negociação que os envolvesse acabava, de maneira direta ou indireta, afetando a todo o continente, independentemente de quem viesse a exercer uma possível liderança regional.

A produção literária focalizando as relações bilaterais entre esses dois Estados, ao longo das décadas, demonstra com muita nitidez os ressentimentos recíprocos e acumulados historicamente. Deve-se, contudo, ressalvar, de um lado, que esta literatura é bastante heterogênea, podendo-se inclusive separar os autores em categorias diversas, como os militares, os jornalistas e os acadêmicos, além de alguns representantes do meio diplomático. De outro lado, o fato de que grande parte dos textos era marcada por posturas agressivas/ defensivas de ambas as partes, convertendo-se em moeda corrente, predominava até meados dos anos oitenta, assumindo comportamento distinto a partir de então.

Obviamente ainda hoje não desapareceram completamente aqueles autores que continuam a refletir adotando os parâmetros anteriores. Alguns militares, por exemplo, ao abordar o intercâmbio entre Buenos Aires e Brasília acabam, na maior parte das vezes, construindo um discurso cauteloso. Chegam mesmo a resvalar em direção a uma postura ufanista, criticando veladamente (às vezes também asperamente) as políticas desenvolvidas pelo outro país, e vendo em muitos gestos do vizinho, constantemente, intenções pouco amistosas ou confiáveis, repetindo o que se passava há anos. É claro que na atual conjuntura, sob a égide da integração, a maior parte dos discursos, embora continue cauteloso, dá ênfase à cooperação, ora em maior nível, ora mais modestamente, dependendo das variações das políticas de ambos os países.

Apenas para efeito ilustrativo, poderíamos falar um pouco sobre esse tipo de reflexão ao longo das últimas décadas sem, contudo, fazer aqui uma avaliação exaustiva, relacionando todos aqueles que trabalharam com o assunto.

\section{O ESTUDO DAS RELAÇÕES INTERNA- CIONAIS ANTES DE 1978}

A participação do Brasil na Guerra do Paraguai, em um período já bastante longínquo, foi sempre um dos motivos utilizados pelos vizinhos latinoamericanos para criticar a atuação brasileira, tida como impiedosa. O professor Leon Pomer, competente historiador argentino e hoje docente da Universidade Estadual Paulista (UNESP), em texto bem elaborado, mostra os interesses em jogo no livro de sua autoria, que tem um título bem chamativo: Um grande negócio (cf. POMER, 1968). Nesse caso, porém, o conteúdo não é de simples crítica, mas uma análise acadêmica um tanto distante da maior parte daquilo que se produziu 
naquela parte do continente. Muitas denúncias seriam feitas com vigor, ao longo dos anos. É, inclusive, provável que as mesmas tenham fundamento, até porque esse é um assunto em que o próprio Ministério das Relações Exteriores se posiciona com cautela, impedindo o acesso a documentação relativa a tal episódio (além de outros).

Após o golpe de Estado em março de 1964, o Brasil vai ser criticado cada vez mais no contexto latino-americano, recebendo o rótulo de "paíschave", "aliado preferencial" dos Estados Unidos etc. As denúncias vão destacar com freqüência o papel do governo brasileiro como gendarme continental, assumindo postura imperialista ou subimperialista, implementando políticas com a finalidade de satelitizar os países da região, objetivando, assim, alcançar supremacia indiscutível no Cone Sul.

Essa literatura focaliza vários temas que seriam as principais preocupações brasileiras: desde a pressão demográfica junto às fronteiras com o Paraguai, com a "migração dirigida" de colonos brasileiros a este país — os "brasiguaios" — ou junto das províncias argentinas de Missiones e Corrientes; os corredores de exportação, cujo intuito seria neutralizar o Paraguai e a Bolívia atendendo aos interesses estratégicos nacionais; o tratado nuclear firmado pelo Brasil com a República Federal da Alemanha em 1975; o investimento no setor bélico através da criação da Indústria de Material Bélico (IMBEL) em 1976, e, principalmente as divergências em torno da construção de Itaipu. Até mesmo Oscar Camilión, depois Chanceler e Ministro da Defesa Argentino, teceu comentários deste gênero (cf. CAMILION, 1973).

Sob este prisma, Itaipu pode ser tomado como bom exemplo para explicar o clima reinante entre os dois Estados mais importantes do continente. Àquela altura, no segundo lustro dos anos setenta, chegou-se inclusive a comentar a possibilidade de as barragens construídas no Rio Paraná servirem como "arma para inundar" a Argentina, abrindose as comportas. O raciocínio, feito sob uma visão estritamente conspirativa, não conseguia perceber que para "inundar" aquele país a própria barragem teria que ser destruída. Mas isso deixaria grande parte do Brasil sem energia elétrica, afetando diretamente toda a economia nacional, visto que nas regiões sul e sudeste se concentrava a maior parte do parque industrial brasileiro. Pensamentos feitos sob este ângulo eram perceptíveis tanto pelo lado brasileiro quanto pelo argentino, não sendo, portanto, privilégio de apenas um deles.

Claro que se deve, também, ponderar que nesses anos o Brasil dava margens a essas interpretações. Em primeiro lugar, considere-se o desastrado discurso feito por Richard Nixon em 1971 na Venezuela, afirmando que para onde o Brasil se inclinasse o resto do continente faria o mesmo; ou seja, conferindo ao nosso País a categoria de país-chave no plano latino-americano. Em segundo lugar, as denúncias de que o Brasil planejara a Operação Trinta Horas, para intervir no Uruguai, caso Liber Seregni ganhasse as eleições; o papel pouco esclarecido do governo brasileiro na queda de Juan Carlos Torres e a ascensão de Hugo Banzer na Bolívia; além dos acontecimentos no Chile, em 1973 (cf. SCHILLING, 1974; GRAEL, 1985). Outros textos produzidos principalmente pelo general Carlos de Meira Mattos, a partir de 1975 , ao lado da "teoria da defrontação" da professora Therezinha de Castro, assumindo o discurso feito pelo deputado federal Eurípedes de Menezes em 1972 defendendo a divisão da Antártica sob diversas bandeiras, reforçavam as ressalvas que os vizinhos tinham em relação à política externa brasileira (cf. CASTRO, 1976; MENEZES, 1972).

Se esta literatura era volumosa, não só por parte do estamento militar, mas também por inúmeros civis exaltando o projeto de Brasil Potência, que era mencionado no plano de governo do general Emílio Garrastazu Médici, o meio acadêmico até então se mantinha extremamente reservado, em função de vários problemas que serão examinados a seguir.

\section{A MUDANÇA NO TRATAMENTO DADO AO ESTUDO DAS RELAÇÕES INTERNA- CIONAIS}

Antes de mais nada, é conveniente lembrar que não se podia falar/escrever abertamente e permanecer impune, sem sofrer conseqüências que poderiam ser drásticas, desde a apreensão da obra até a perda de emprego, sem contar uma possível abertura de processo, incluindo prisão e tortura. Um dos livros do empresário Kurt Mirrow, por exemplo, denunciando os cartéis no País foi recolhido imediatamente após o seu lançamento (cf. MIRROW, 1977). Outros casos envolvendo a censura aos grandes jornais como $O$ Estado de $S$. Paulo, Jornal da Tarde e Tribuna da Imprensa e 
aos da imprensa nanica como Opinião e Movimento, faziam parte da rotina, já que o clima de exceção em que o País estava mergulhado dava margens para que o governo assim agisse.

Mas também havia outro motivo pelo qual o meio acadêmico pouco se manifestava — mesmo se desejasse e fosse possível - a respeito da atuação brasileira quer no cenário regional, quer no nível mais amplo do sistema internacional. Praticamente não havia pessoas ligadas à Universidade com possibilidade de fazer boas análises sobre a maior parte dos assuntos que diziam respeito à política externa brasileira e, pior ainda, sobre as Relações Internacionais lato sensu. $\mathrm{Na}$ realidade, verificava-se que tanto a prática quanto a teoria constituíam-se quase um monopólio dos diplomatas do Ministério das Relações Exteriores.

Isto não significa que não houvesse produção sobre o assunto. Certamente sim, mas ela se referia quase sempre a aspectos históricos, a períodos mais remotos, e os colegas historiadores continuaram dando valiosa contribuição, mesmo nesse período. Os juristas, os diplomatas e os economistas também escreviam sobre o tema, e seria injusto deixar de mencioná-los, como pode ser verificado em publicações como a Revista Brasileira de Política Internacional, que era dirigida desde 1958, inicialmente por Oswaldo Trigueiro e no final por Cleantho de Paiva Leite, através do Instituto Brasileiro de Relações Internacionais, criado quatro anos antes. Além dessa, a Revista de Ciência Política da Fundação Getúlio Vargas (RJ) e a Revista Brasileira de Estudos Políticos, da Universidade Federal de Minas Gerais, tendo a sua frente Orlando de Carvalho, igualmente se dedicavam a publicar, de forma esparsa, artigos sobre política externa brasileira, inclusive o conhecido texto de J.A Araujo Castro sobre o congelamento do poder mundial no começo dos anos setenta (cf. ARAUJO CASTRO, 1972).

Todavia, o número de cientistas políticos, de acadêmicos especializados em Relações Internacionais ainda era reduzido, entre os quais se destacavam: José Honório Rodrigues, Carlos Delgado de Carvalho, Luiz Moniz Bandeira, José Carlos Brandi Aleixo e Hélio Jaguaribe. Mesmo hoje a situação não é a ideal, mas o quadro já é bem melhor do que antes, sem qualquer sombra de dúvida, tanto em termos quantitativos quanto qualitativamente.
Alexandre de Barros em um primeiro balanço da produção na área, com boas informações, relembra estes dados. Mencionava inclusive o caso da Fundação Ford que patrocinou a ida de algumas dezenas de jovens profissionais para que estudassem nos EUA e, após solidificar seus conhecimentos, promovessem o avanço da área no Brasil (cf. BARROS, 1985). É interessante ressaltar, diz Alexandre de Barros, que de todos que para lá foram, apenas dois acabaram se dedicando à área stricto sensu de Relações Internacionais: a professora Maria Regina Soares de Lima, do Instituto Universitário de Pesquisa do Rio de Janeiro (IUPERJ), e Henrique de Souza Novaes, este mais voltado para atividades jornalísticas e de assessoria a fundações e, principalmente, a grandes empresas brasileiras no exterior (cf. BARROS, 1985). Os demais dedicaram-se ao estudo e à divulgação da Ciência Política lato sensu ${ }^{2}$.

A área de Relações Internacionais no meio acadêmico padecia, então, de carência de recursos humanos suficientes para que pudesse desenvolver-se a contento e constituir-se em programas de ensino e pesquisa nas diversas universidades. Isto pode ser observado pela morosidade com que as disciplinas passaram a ser ministradas (ainda hoje as dificuldades são grandes) nas diferentes instituições nacionais, fossem elas estaduais ou federais.

Apenas para exemplificar, somente em 1973 se passou a oferecer como cadeira eletiva, sob responsabilidade do professor Oliveiros Ferreira, uma disciplina semestral intitulada "Relações Internacionais" na graduação em Ciências Sociais da Universidade de São Paulo. Este primeiro curso foi imediatamente seguido por outro que dava ênfase mais à política praticada em âmbito continental, com os Estados Unidos ocupando papel de destaque no programa. Conquanto houvesse um grande número de alunos inscritos, a frequiência deixava muito a desejar. Ministradas até 1982, estas disciplinas só tiveram continuidade nos anos noventa, agora com o professor Leonel Itaussu Almeida Mello, que também atua na pós-graduação. Os professores José Augusto Guilhon Albuquerque e Braz José Araujo, também, em diferentes

\footnotetext{
2 Sobre o desenvolvimento da Ciência Política no País, ver FORJAZ, 1997. Ver, também, LAMOUNIER e CARD OSO, 1978.
} 
períodos, dedicaram-se a esta área na graduação, concentrando seus interesses, posteriormente, na pós-graduação, principalmente na orientação de alunos e coordenação de núcleos de estudos.

Naquela época não havia sequer o Departamento de Ciência Política como instância autônoma, o que se verificou apenas a partir de meados dos anos oitenta. O mesmo também se observava na Universidade de Campinas (UNICAMP), quando somente no início dos anos noventa foi criado o Departamento de Ciência Política, desmembrando-se o Departamento de Ciências Sociais nas três áreas tradicionais, Antropologia, Sociologia e Ciência Política.

Na Pontifícia Universidade Católica de São Paulo (PUC/SP), também no mesmo ano de 1973 começou a ser oferecida uma disciplina com o título de "Política Internacional", no $8^{\circ}$ semestre da graduação em Ciências Sociais, e que perdurou até 1987. Nesta última instituição a disciplina foi ministrada, em diferentes momentos, por professores que, apesar das formações diversificadas, trabalhavam na área, como Vicente Marotta Rangel e Guido Soares (ambos juristas), Leon Pomer (historiador) e Tullo Vigevani (historiador e cientista político). Na Universidade Federal do Pará, também uma disciplina com o título de "Política Internacional" foi introduzida no currículo de Ciências Sociais nos anos oitenta.

Além desses, existiam apenas os tradicionais cursos de Direito Internacional ministrados, por exemplo, em faculdades como a do Largo de São Francisco (São Paulo), mas que estavam longe de atender aos interesses de alguém que se sentisse mais atraído pelas vertentes históricas e políticas. Ao longo dos anos, as faculdades de Direito irão abrigar um grande número de docentes que trabalharão com inúmeras questões sobre Relações Internacionais, como Celso Lafer e Celso Albuquerque de Mello, além de dezenas de outros, e que seria impossível aqui listar.

A área de Economia Internacional, por sua vez, sempre teve espaço maior nos próprios currículos, principalmente pelo fato de o País, a partir dos anos setenta, dar grande importância à exportação. Aliás, inclusive na esfera governamental, o Itamaraty criou, com Paulo Tarso Flecha de Lima, o Departamento de Promoção Comercial em 1971.

Na verdade, não era apenas a área de Relações Internacionais que se sentia restringida, até porque praticamente não existia. A Ciência Política como um todo - e as outras Ciências Humanas igualmente - sofria as consequiências da repressão nas universidades, que pode ser lembrada pelas inúmeras cassações desde 1964. Evidentemente que se deve ponderar que a Ciência Política no Brasil também é muito recente, daí o modesto número de profissionais na área de Relações Internacionais oriundos da primeira. Alguns que se interessavam pelas Relações Internacionais se achavam concentrados nos departamentos de História, de Economia e de Direito, principalmente dos grandes centros como Rio de Janeiro, Brasília, Belo Horizonte e São Paulo.

Se isto era perceptível no nível interno, o mesmo já não se podia dizer no plano externo. Enquanto a preocupação dos cientistas nacionais era com o regime de exceção, detendo-se em temas tradicionais como a questão fundiária, o sindicalismo, os partidos políticos e os aspectos políticoinstitucionais, principalmente nos Estados Unidos um grande número de pesquisadores começou a voltar suas atenções para o Brasil, surgindo então os "brazilianistas" que passaram a explorar inúmeras facetas do País. Duas dessas diziam respeito aos interesses mais próximos a nós: a política das forças armadas e as relações externas. Surgiram, de um lado, obras como a de Alfred Stepan, discorrendo sobre os militares e, de outro, trabalhos sobre o papel jogado pelo País (ou a desempenhar) no cenário internacional, seja sob o ângulo mais histórico, como o de Stanley Hilton, ou então de professores como Wayne Selcher, Roger Fontaine e Ronald Schneider; e dezenas de outros que poderiam ser aqui listados, como Philippe Schmitter, Thomas Skidmore, Warren Dean, Joseph Love, John Wirth etc., mais preocupados em explicar a dinâmica da política interna, tanto em termos estaduais, quanto no âmbito nacional.

O motivo para esse aumento do interesse norteamericano pelo Brasil pode ser creditado a um fato particular. Enquanto os cientistas brasileiros estavam mais interessados em debater o processo político interno, preocupados com a duração do regime e temas semelhantes, a economia nacional crescia a ritmos acelerados no período que vai de 1969 a 1973, passando a ser uma das dez maiores do mundo. Isto era um dado real - que, certamente, não contemplava o regime de exceção, as disparidades socioeconômicas etc. —, um elemento concreto visto pelos acadêmicos do exterior, pelos governos e pelos investidores estrangeiros. 
Daí a necessidade de melhor se entender o País, com generosos recursos financeiros e materiais colocados à disposição desses pesquisadores, além das facilidades para contatar e entrevistar autoridades brasileiras, sobretudo militares ${ }^{3}$.

Em outros locais, como na Bélgica, no Canadá e na Suécia, também se produziram estudos sobre o período, como as obras de Michel Schooyans sobre o estamento militar e a ditadura (cf. SCHOOYANS, 1973).

Esta diferença de interesse para se analisar políticas internas e políticas externas é perfeitamente compreensível. Enquanto os pesquisadores que enfrentam a situação de regimes ditatoriais fecham-se em torno de problemas domésticos, os estrangeiros, além dessas preocupações, tiveram, pelo menos naqueles anos, propensão em estudar o papel exercido pela diplomacia e pelo comércio exterior brasileiros, tanto no âmbito latino-americano quanto no continente africano, ou então de maneira mais ampla, especulando-se inclusive sobre o futuro do Brasil.

No plano diplomático, o acesso à documentação guardada pelo Itamaraty tinha também prazos diferentes para consultas, se interessados nacionais ou estrangeiros, com tempos de cinquienta e trinta e cinco anos respectivamente, além de temas proibidos, sob a rubrica de "segurança nacional".

Nos anos setenta, as mudanças no plano político-institucional, com o fim da censura e a política de abertura "lenta e gradual", como se dizia no governo do general Ernesto Geisel, bem como eleições livres e diretas em 1974, (logo sufocadas pela Lei Falcão e pela indicação do senador biônico), a anistia em 1979, o final dos atos de exceção e a alteração do sistema partidário, fizeram com que a área de Relações Internacionais passasse a ocupar maiores espaços. Mesmo porque já se tinha consciência de que, bem ou mal, apesar das disparidades socioeconômicas internas, o Brasil se tornara conhecido no mundo. E isto era um fato irreversível. Portanto, não se podia

3 Como exemplo, pode-se recordar o caso de Alfred Stepan que, ao final dos anos sessenta, conseguiu entrevistar metade do ministério do marechal Castelo Branco em período bem diminuto, enquanto nenhum pesquisador brasileiro tinha acesso a esses personagens (cf. STEPAN, 1974). mais ignorar estes acontecimentos, e também para que as interpretações não ficassem restritas às visões dos brazilianistas. Por isso, a partir de meados dos anos setenta a área de Relações Internacionais e as que diziam respeito a questões estratégico-militares passaram a adquirir maior importância, ainda que de forma modesta.

A Universidade de Brasília, pelo seu próprio locus, já se antecipava e criava o curso de graduação em Relações Internacionais em 1974, enquanto o seu Departamento de História se preocupava com esta temática na pós-graduação. No Rio de Janeiro, haviam ocorrido, também, algumas tentativas de criação de faculdades de Relações Internacionais, mas que, devido à discutível qualidade do ensino ministrado, foram sucessivamente fechadas (cf. BARROS, 1985).

Curiosamente, apesar de no Rio de Janeiro se verificar tal interesse, bem como em Brasília, o mesmo não se podia dizer de São Paulo, que até então se mantinha um tanto insensível à matéria. Embora o estado se constituísse em importante centro econômico-industrial, político e cultural, ocorria uma defasagem entre estes fatos e o interesse por assuntos internacionais no meio acadêmico. Nos anos noventa, porém, a situação será completamente distinta, conforme comentaremos depois.

No Rio de Janeiro existem atualmente apenas duas instituições voltadas para o estudo das Relações Internacionais (Faculdades Estácio de Sá e Escola de Relações Internacionais da Faculdade da Cidade do Rio), enquanto a PUC/RJ oferece tão somente disciplinas isoladas ministradas por Letícia Pinheiro e Mônica Herz. Outros profissionais, contudo, podem ser encontrados na Universidade Federal Fluminense (René Armand Dreiffus, Williams da Silva Gonçalves e Luís Manuel Rebelo Fernandes), na Universidade Estadual do Rio de Janeiro (Míriam Gomes Saraiva) e na própria PUC (entre os quais Sônia de Camargo e José Maria Gomez, além dos mencionados ao longo deste texto). Em outras localidades, como na Universidade Federal do Rio Grande do Sul (Paulo Vizentini), na Universidade Federal do Paraná (Rafael Antonio Duarte Villa), ou na Universidade Federal de Santa Catarina (Hector Leis e Waldir José Rampinelli), os esforços continuam sendo feitos isoladamente.

Na década de 1970, na Câmara Federal, através da Comissão de Relações Exteriores, realizaram- 
se dois grandes painéis discutindo a ordem mundial, em 1975 e 1977, cujos resultados foram posteriormente publicados pela instituição (cf. BRASIL. CÂMARA FEDERAL, 1975 e 1977).

Na Fundação Getúlio Vargas de São Paulo, em 1975, também se organizou seminário com grande número de especialistas internacionais, tendo os textos sido publicados em 1978 com o título de $A$ crise da ordem mundial (cf. RATTNER, 1978).

Em outras instâncias, com o apoio do Instituto Universitário de Pesquisas do Rio de Janeiro (IUPERJ), do Programa de Estudos Comparados Latino-americanos da Universidade Federal de Minas Gerais, do Instituto Latino-americano de Desenvolvimento Econômico e Social (ILDES) e da Fundação Ford se realizaram dois grandes seminários em 1977 e 1978 em Nova Friburgo (RJ) reunindo pesquisadores brasileiros, norteamericanos, argentinos e alemães. No segundo encontro, foi criado o Conselho Brasileiro de Relações Internacionais (atualmente dirigido por Fernando Augusto Albuquerque Mourão, também editor da revista África, do Centro de Estudos Africanos da USP), tendo como signatários da proposta inicial, entre outros, Maria Regina Soares de Lima, Hélio Jaguaribe, Cleantho de Paiva Leite, Celso Lafer, José Carlos Brandi Aleixo, Carlos Henrique Cardim, Franklin Trein, Christian Caubet, além do próprio autor deste artigo.

Em São Paulo realizava-se, em 1979, grande encontro discutindo questões militares e estratégicas, organizado pela Sociedade Brasileira de Cultura Convívio; repetido quatro anos depois, o segundo seminário serviu, ainda, para o lançamento da revista Política e Estratégia, cujo número inicial reunia os textos apresentados na primeira ocasião, contendo reflexões de pesquisadores estrangeiros e brasileiros, além de vários estudos assinados por militares da reserva, como o general Carlos de Meira Mattos, que chegou a defender a idéia de que "o Brasil era ainda um Estado em expansão” (cf. MEIRA MATTOS, 1983).

Algumas teses também já estavam sendo elaboradas, por exemplo, por Christian Caubet sobre a barragem de Itaipu, seguindo os trilhos percorridos por Laerte Bettiol, que tinha feito o mesmo (cf. BETIOL, 1983; CAUBET, 1991). Tratava-se já de duas boas reflexões sobre tema que dizia respeito às relações Brasil-ArgentinaParaguai, e que escapavam ao âmbito exclusivo das interpretações diplomáticas e da imprensa.
Algumas leituras bastante interessantes sobre a política externa brasileira também tinham sido feitas recentemente, entre outros, por Carlos Estevam Martins, sobre a política exterior brasileira dos anos sessenta/setenta, enquanto Octávio Ianni refletia de maneira diferente comentando o imperialismo norte-americano na América Latina (cf. MARTINS, 1975; IANNI, 1974); Ruy Mauro Marini discorria sobre o subimperialismo brasileiro em 1974 (cf. MARINI, 1974).

Esses trabalhos, importantes naquele momento, abordavam a atuação brasileira principalmente no Cone Sul, mas converteram-se em esforços praticamente isolados, inclusive com os autores dedicando-se, posteriormente, a outras indagações, chegando mesmo a abandonar a área. Desses, apenas Octávio Ianni nos anos noventa dirigiu seu olhar para vários aspectos da globalização, nisto muitas vezes dialogando com Renato Ortiz, da UNICAMP.

$\mathrm{Na}$ Universidade Federal Fluminense foram ministradas disciplinas isoladas sobre Relações Internacionais, criando-se no Centro de Pesquisa e Documentação Contemporânea da Fundação Getúlio Vargas (CPDOC), em 1980, o Programa de Relações Internacionais sob supervisão de Gerson Moura e Mônica Hirst (esta última, desde os anos oitenta, está na Facultad Latinoamericana de Ciencias Sociales - Flacso - de Buenos Aires) à frente de outros pesquisadores. $\mathrm{O}$ Centro de Documentação sobre a América Latina (CEDAL), da Universidade de São Paulo, igualmente se voltava para os temas regionais, promovendo cursos de extensão a partir de 1973.

Em 1980, também, se reunia nas dependências da Universidade Estadual do Rio de Janeiro, no interior da Associação Nacional de Pós-graduação e Pesquisa em Ciências Sociais (ANPOCS), pela primeira vez o Grupo de Trabalho sobre Relações Internacionais e Política Externa (GRIPE).

Essa primeira tentativa no seio do GRIPE/ ANPOCS apresentava uma grande heterogeneidade de interesses, tanto temáticos, quanto de universidades e de investigadores isolados, sinalizando a necessidade de se reunir mais metodicamente os esforços individuais desses pesquisadores.

As constantes alterações ocorridas na dinâmica de reuniões da ANPOCS, ora com grupos de trabalho, ora com "seminários temáticos" fez, con- 
tudo, que em 1994 o GRIPE fosse excluído. Pesquisadores isolados apresentaram-se ocasionalmente em algumas mesas-redondas. A justificativa na época para a recusa da proposta do GRIPE fora a de que se tratava de assunto "pouco interessante" e estava mal elaborada, segundo a Secretaria da entidade, embora o eixo central das discussões estivesse orientado para o tema da globalização. A partir do ano passado, contudo, o grupo, com a nova designação de "Política Internacional" teve sua presença assegurada no âmbito da ANPOCS até o ano 2000.

Naquela primeira reunião do GRIPE esteve também presente Gelson Fonseca Júnior, então primeiro-secretário do Itamaraty, e, desde 1989, assessor de Relações Internacionais da Presidência da República. Nos anos oitenta e noventa, a presença de diplomatas, seja através do Instituto de Pesquisa sobre Relações Internacionais (IPRI), pela Fundação Alexandre de Gusmão, seja pelo Instituto Rio Branco, será uma constante nas reuniões acadêmicas. Esta estreita colaboração resultará em inúmeros seminários, grupos de trabalhos, publicações, palestras etc., e que irão contribuir significativamente para o avanço da área fora dos tradicionais redutos diplomáticos. $\mathrm{O}$ mesmo se verificará, posteriormente, inclusive, com o Ministério Extraordinário de Projetos Especiais (exSecretaria de Assuntos Estratégicos (SAE)), que passou a abrigar um número elevado de pessoas com formação acadêmica ou interessadas em Relações Internacionais, bem como inúmeros diplomatas, como o próprio ministro atual, Ronaldo M. Sardenberg, e o conselheiro Carlos Henrique Cardim, coordenador do Centro de Estudos Estratégicos desse Ministério. Deve-se mencionar, ainda, que o número de diplomatas brasileiros que tem produzido textos sobre Relações Internacionais é bastante numeroso, bastando para isso conferir as publicações do próprio IPRI.

Sobre as questões levantadas nos parágrafos anteriores, tanto Alexandre de Barros, quanto José Flávio Sombra Saraiva e Paulo Roberto de Almeida já publicaram excelentes trabalhos abordando não só as instituições que ao longo do tempo trabalharam com Relações Internacionais, mas arrolando as publicações e os próprios programas de graduação e pós-graduação existentes no País, motivo pelo qual escusamo-nos de continuar repetindo aqui seus argumentos, ou apenas relacionando novos seminários e instituições (cf. BARROS, 1985; SARAIVA, 1997, p. 17-58; ALMEIDA,
1993, p. 162-169).

\section{O ESTUDO DAS RELAÇÕES INTERNACIO- NAIS NOS ANOS RECENTES}

Os anos recentes experimentaram um incremento vigoroso da área de Relações Internacionais no País. Alguns acontecimentos podem ajudar a explicar melhor o quadro atual do "estado das artes". Em primeiro lugar, o processo de integração envolvendo Brasil e Argentina em meados da década passada e que, ampliado, deu lugar ao Mercosul; em segundo lugar, a estabilidade econômica, que favoreceu a formulação de políticas externas em bases mais sólidas; e, em terceiro lugar, o próprio processo de globalização/regionalização. Além, é claro, de outros temas que, levados a conhecimento público, tem incentivado alunos tanto de graduação, quanto de pós-graduação, em nível de mestrado e doutorado, a desenvolver projetos de pesquisa contemplando temas específicos em Relações Internacionais. Entre esses poderíamos arrolar a queda do muro de Berlim, o conflito na Bósnia, a guerra Grã-Bretanha versus Argentina, a guerra do Iraque contra o "resto do mundo", o fim do apartheid na África austral, o terrorismo, o problema da fome em grande parte do continente africano, as migrações internacionais, o tráfico de drogas, a questão ambiental, os nacionalismos etc.

No que diz respeito ao primeiro caso, os protocolos de integração brasileiro-argentino assinados pelos então presidentes José Sarney e Raul Alfonsín fizeram com que a região se tornasse alvo de interesse não só acadêmico, mas também político e, sobretudo, econômico. Afinal de contas, começou-se a falar em um mercado livre, o que significava mais algumas dezenas de milhões de potenciais consumidores junto às fronteiras internacionais do Brasil.

No Rio Grande do Sul criou-se inclusive a Secretaria de Assuntos Internacionais, ocupada inicialmente por Ricardo Seitenfus, então professor da Universidade Federal do Rio Grande do Sul e que, atualmente, coordena o Mestrado em Integração Latinoamericana da Universidade Federal de Santa Maria. Não é sem motivo, portanto, que se passaram a verificar nessa universidade, sobretudo nos anos mais recentes, inúmeras iniciativas relacionadas à participação do País no Mercosul, seja através de cursos e seminários, seja por intermédio de convênios firmados com outras instituições, assumindo importante papel no processo de integração regional. 
A variável militar, por sua vez, ficou relegada a um plano secundário, mesmo porque militares sempre pensam os problemas do Estado sob ótica muito particular, daí as eternas desconfianças quando se fala em integração, formação de blocos, forças armadas conjuntas etc. $\mathrm{O}$ espírito conspiratório normalmente acaba prevalecendo neste caso, havendo, portanto, um descompasso temporal no cumprimento das metas de integração regional nos planos econômico, político e militar.

Principalmente nos anos noventa, o controle do processo inflacionário e o ajuste gradual das contas nacionais, bem como uma série de outras providências tomadas em planos diversos, fizeram com que a estabilidade econômica assumisse importância e se começasse a pensar uma política externa "mais consistente". Quer dizer, tentando fazer com que o País passasse a aspirar papel de maior relevo no cenário internacional, inclusive reivindicando em determinados momentos até mesmo uma vaga como membro cativo do Conselho de Segurança da Organização das Nações Unidas. É bem verdade que a grande turbulência sofrida pela economia brasileira no início de 1999, com a desvalorização do real, ainda terá reflexos na conduta da política externa.

Estes fatos fizeram com que alguns pesquisadores também se sentissem atraídos para estudar esta nova faceta da atuação brasileira no quadro mundial, com o País tentando aumentar seu grau de credibilidade, ou ocupando espaços como potência média. O País procurava com isto captar mais recursos tentando, ao mesmo tempo, mostrar que eventualmente estaria já amadurecido e preparado para assumir novas responsabilidades em todos as esferas, tanto no plano político, quanto econômico. A política externa brasileira converteuse, assim, em alvo de interesse de vários jovens profissionais, ligados tanto às universidades, quanto aos centros de pesquisa espalhados pelo País.

Além dessas duas variáveis, o processo que se convencionou chamar de "globalização" passou a atrair intensamente a atenção de estudiosos das mais diferentes áreas para o que estava se verificando no mundo desde há algum tempo, mas com força cada vez maior, questionando-se então o próprio Estado Nacional.

Esta preocupação fez com que um grande número de pesquisadores em boa parte das universidades começasse a dedicar ênfase espe- cial ao assunto ainda que nem todos sejam stricto sensu da área de Relações Internacionais. A palavra globalização passou, destarte, a ser associada a todos os temas, desde questões de gênero a problemas ambientais, de preocupações com as populações indígenas até o novo papel dos sindicatos, não se esquecendo dos tópicos relacionados à saúde, à educação, à previdência. A globalização tornou-se, assim, uma palavra mágica para explicar tudo o que ocorre no mundo, em termos econômicos, políticos, militares, culturais, sociais etc.

Uma comparação das duas últimas décadas tomando como ponto de referência (arbitrariamente) o ano de 1978, quando se cria o Conselho Brasileiro de Relações Internacionais - com o período anterior, vai nos indicar claramente (ainda que fosse conveniente realizar um mapeamento completo apontando temas, número de pesquisadores envolvidos, publicações etc.) que houve substancial acréscimo em todos os indicadores citados. Aumentou sensivelmente a quantidade de pessoas interessadas em Relações Internacionais, no âmbito das universidades e das instituições de pesquisas, evidenciado pelo volume de dissertações e de teses defendido e em andamento; os temas se diversificaram e a quantidade de publicações também foi incrementada. Não se pode esquecer, ainda, que representantes do meio acadêmico ocuparam, inclusive, cargos em instituições profissionais, como o professor Cândido Mendes, na presidência da Associação Internacional de Ciência Política (IPSA), e Clovis Brigagão, secretariando a Associação Internacional de Pesquisa para a Paz (IPRA) na década de oitenta.

Deve-se, contudo, fazer algumas ressalvas perante um quadro que, em princípio, poderia parecer muito satisfatório.

No que tange a revistas há uma série de títulos, desde aqueles com cunho voltado mais para preocupações: (i) estratégico-militares, como $A$ Defesa Nacional (publicada desde 1913), a Revista Marítima Brasileira (do século passado), Segurança e Desenvolvimento (da Associação dos Diplomados da Escola Superior de Guerra (ADESG), editada desde 1951, anteriormente com o nome de Revista da ADESG), Revista da ESG (Escola Superior de Guerra, publicada desde 1985), Cadernos CEBRES (Centro Brasileiro de Estudos Estratégicos, edições irregulares desde 1982), Premissas, do Núcleo de Estudos Estratégicos da Universidade Estadual de Campinas (desde 
1992), Cadernos NAIPPE (do Núcleo de Análise Interdisciplinar de Políticas e Estratégias da USP), Estudos Afro-Asiáticos (da Universidade Cândido Mendes, desde 1978, e editado atualmente por José Maria Nunes Pereira), Contexto Internacional (desde 1985) do Instituto de Relações Internacionais da PUC/RJ, Política Externa (desde 1992), da USP; (ii) culturais, como Nossa América, do Memorial da América Latina; e (iii) publicações das Federações de Comércio e da Indústria, do Instituto de Pesquisa sobre Relações Internacionais do Ministério das Relações Exteriores (entre as quais os relatórios de pesquisa e mesmo teses acadêmicas em co-edição), Foreign Affairs e Semanário do Mercosul, ambos da Gazeta Mercantil (desde 1996), além de outras.

Muitas dessas publicações são (ou foram) editadas de maneira muito irregular, sazonalmente, quando não desapareceram simplesmente após breve experiência. Entre essas, cito a própria Política Externa Independente, com três números em 1965, o mesmo ocorrendo com América Latina da Universidade Federal de São Carlos, e a revista da UnB (Relações Internacionais, com apenas cinco números, entre 1978 e 1980), enquanto a Revista Brasileira de Ciência Política circulou com apenas um exemplar em 1989.

Outra publicação que se encarregava de divulgar documentos internacionais, a Textos \& Documentos, editada por Rogê Ferreira entre 1979 e 1981, saiu de circulação por não existir apoio, conforme disse o editor ao autor deste texto. A Política e Estratégia também não conseguiu resistir (19831990), enquanto o suplemento mensal Internacional do Correio Braziliense editado nos inícios dos anos noventa (1992-1994), reunindo contribuições significativas do meio acadêmico, não seguiu avante. A própria Revista Brasileira de Política Internacional (atualmente dirigida por Amado Luiz Cervo), apenas sobreviveu graças à iniciativa de colegas da UnB após a morte de Cleantho de Paiva Leite. Por outro lado, não se pode esquecer o papel importante desempenhado pela Editora da Universidade de Brasília que editou inúmeras obras consideradas fundamentais para o estudo das Relações Internacionais, como os textos de Raymond Aron, Karl Deutsch e Edward Carr. Atualmente a Editora da UFRGS publica, coordenada por Paulo G. Fagundes Vizentini, a coleção "Relações Internacionais e Integração", tendo já lançado dois títulos sobre política externa brasileira (de Paulo Vizentini e Paulo Roberto de Almeida), enquanto a Editora Vozes mantém há algum tempo a coleção "Horizontes da Globalização". Mesmo o Centro de Estudos Estratégicos que edita Parcerias Estratégicas também abriu uma série intitulada "Estratégia e Política Internacional". A Fundação Konrad Adenauer de São Paulo tem, também, publicado inúmeros livros e ensaios sobre Relações Internacionais, tanto sobre o continente latinoamericano, quanto sobre a realidade européia.

Quanto às instituições, também as variações denotam um quadro de certa maneira preocupante. Se não estiverem ligadas às universidades ou a setores empresariais como a Federação das Indústrias do Estado de São Paulo, o que se verifica é o surgimento e o seu desaparecimento alguns anos depois. Por exemplo, o Centro de Estudos Estratégicos da Sociedade Brasileira de Cultura Convívio - foi desativado quando os responsáveis/interessados na área, como Antônio Carlos Pereira, se desligaram dessa instituição e ajudaram a fundar o Instituto Brasileiro de Assuntos Estratégicos no começo dos anos noventa, hoje também praticamente inativo. Por outro lado, as entidades vinculadas a órgãos governamentais, como a exSecretaria de Assuntos Estratégicos, tem demonstrado fôlego pouco maior, ajudando e promovendo inúmeros seminários, inclusive lançando cadernos de debates e o periódico Parcerias Estratégicas, já no seu quinto número (dirigida por Carlos Henrique Cardim); o Instituto de Pesquisa sobre Relações Internacionais (IPRI), a USP (também por intermédio da área de Relações Internacionais do Instituto de Estudos Avançados), o Centro de Estudos das Américas da Universidade Cândido Mendes (que conta com a presença de Clovis Brigagão, Juarez Coqueiro, Severino Cabral e Jacques d'Adesky), a PUC/RJ e a UNICAMP têm publicado regularmente revistas, cadernos e cartas, com periodicidades diferentes (mensais, trimestrais, quadrimestrais ou semestrais). Seminários têm sido promovidos em todo o País com regularidade, inclusive realizando-se os Encontros Nacionais de Estudos Estratégicos, cuja quarta versão aconteceu na Universidade de Campinas em maio de 1998, e coordenado pelo Núcleo de Estudos Estratégicos.

É bem verdade que nesses locais também ocorrem problemas. A Universidade de Campinas pode ser tomada como bom exemplo para explicar freqüentes divergências sobre o entendimento que se têm sobre a importância ou não do campo de trabalho focalizado neste artigo. Um dos centros 
de pesquisa, o Núcleo de Estudos Estratégicos (atualmente coordenado por Eliézer Rizzo de Oliveira) foi criado através de portaria do Reitor GR 059/85, de 28 de março de 1985, em função de três eixos: a estratégia, as forças armadas e as Relações Internacionais. Contudo, esta ultima área foi simplesmente excluída pelo ex-coordenador em 1987, sob a alegação de a mesma "não ter perfil", como se pode constatar pelos relatórios internos da entidade, só sendo reativada em 1994, agora com o nome de "Politica Internacional". Mesmo recentemente a área "Relações Internacionais e Política Comparada", que constava como linha de investigação do Departamento de Ciência Política, teve seu nome alterado ao se fundir com a área de "Forças Armadas, Estado e Sociedade" em uma única linha de trabalho com o título "Estudos internacionais e militares".

Mas se as revistas/publicações têm tido uma certa irregularidade, no que se refere aos cursos, o quadro tem sido mais animador. Pelo menos em parte. Em meados dos anos setenta, existia apenas um curso de graduação em Relações Internacionais na UnB e, posteriormente, pós-graduação neste mesmo local e na PUC/RJ.

Mas outras universidades de igual porte, como a USP, a UNICAMP e a UNESP, apesar de terem seus centros e núcleos de pesquisa, não conseguiram consolidar programas semelhantes, tendo poucos docentes especializados, sendo ministradas disciplinas isoladas não constituindo um programa visando obter títulação específica em Relações Internacionais nos dois níveis, de graduação e de pós-graduação ${ }^{4}$. Na UNESP, no campus de Araraquara, o esforço também é isolado, contando com poucos docentes como Luis Fernando Ayerbe, da área de Estudos Latino-americanos. O contrário já acontece na própria Universidade de São Paulo com o Mestrado em Integração Latino-americana (PROLAM), o mesmo se verificando na Universidade Federal de Santa Maria, enquanto na Universidade de Passo Fundo há o Programa de Pósgraduação em Mercosul e Desenvolvimento Re-

4 Na USP, a área temática da pós-graduação de Relações Internacionais e Estudos Estratégicos tem apenas três docentes, dos quais dois são coordenadores do Núcleo de Pesquisa em Relações Internacionais e Política Comparada (NUPRI) e do NAIPPE, José Augusto Guilhon Albuquerque e Braz José Araujo, respectivamente. gional, as duas últimas no Rio Grande do Sul. Ou ainda, através das linhas de trabalho oferecidas pelos Departamentos de História da Universidade de Brasília desde meados dos anos setenta, na pósgraduação, com um corpo docente altamente qualificado.

Em outras instituições como na UNICAMP, na Universidade Federal de Minas Gerais, no IUPERJ, na PUC/SP, na UFRGS, na UFSC, nos programas de pós-graduação em Ciências Sociais/Ciência Política existem apenas linhas de trabalho ou subáreas contemplando as Relações Internacionais. Na Universidade Luterana do Brasil (ULBRA) há uma linha de doutorado contemplando os Estudos Internacionais, enquanto na Universidade Federal do Rio de Janeiro, nos Programas de Pós-graduação em Engenharia (COPPE), existe também um Grupo de Estudos Estratégicos, coordenado pelo professor Domício Proença Júnior.

Sem sombra de dúvida, é na Universidade de Brasília que se concentra o maior número de profissionais experimentados na área, como Eiiti Sato, Marcus Faro de Castro, Antônio Cançado Trindade, Albene Miriam Menezes, Eduardo Viola, Lytton Guimarães, Argemiro Procópio Filho, Maria das Graças Rua, Nielsen de Paula Pires, além dos mencionados anteriormente ${ }^{5}$.

É alentador o número de cursos de pósgraduação lato sensu oferecidos principalmente sobre a integração latino-americana que já se verificava na UnB desde os anos oitenta. Mencionese aqui os cursos recentes da USP a partir de 1997, os da UFRGS, bem como os de especialização na Universidade Estadual do Rio de Janeiro (apesar de contar com apenas dois conceituados professores, Williams da Silva Gonçalves e Miriam Gomes Saraiva); no mesmo nível, a Fundação Escola de Sociologia e Política de São Paulo oferece o curso de "Política Internacional", (coordenado

5 No Departamento de Relações Internacionais da UnB existe um total de 27 docentes (contando-se os afastados e pesquisadores associados). São membros, Adriano Benayon do Amaral, Antonio Carlos M. Lessa, Carlos Roberto P. da Costa Filho, Danilo Von Sperling, José Francisco Rezek, Julie S. Zapata, Marcio F. Nunes Cambraia, Maria Helena C. Santos, Maria Izabel V. de Carvalho, Marilia Coutinho, Marta Zador, Mauro Pereira Porto, Paulo R. C. Kramer, Rubens Ricupero e Sérgio S. Amaral, além dos já mencionados no corpo do texto. 
por Nanci Valadares), já em sua sétima edição; e os cursos de extensão ministrados pelo Núcleo de Pesquisa em Relações Internacionais da USP, por jovens pesquisadores que realizam simultaneamente seu doutorado (como Flávia de Campos Mello, Janina Onuki, Ricardo Sennes, Amâncio Jorge de Oliveira e Cristina Pecequillo), tendo como objeto de investigação temas relativos à política externa brasileira, ao Mercosul e correlatos.

Os cursos de graduação, igualmente, sofreram um aumento extremamente significativo. Apenas nos últimos anos, principalmente, no segundo lustro dos anos noventa, várias universidades criaram bacharelados em Relações Internacionais, como a PUC/SP (coordenado por Paulo Edgar Almeida Resende), a Universidade do Sul de Santa Catarina (UNISUL), a Universidade São Marcos (São Paulo), a Fundação Armando Álvares Penteado, o Unibero - Centro Universitário Iberoamericano, a Faculdade Santa Marcelina, a Universidade Católica de Brasília, a Universidade do Vale do Itajaí (UNIVALI), a PUC/MG e a Unidomus, do grupo Pueri Domus de São Paulo. Encontram-se, também, em discussão projetos de criação de cursos nos campi da Universidade Estadual Paulista em Franca e Marília, além de pelo menos mais uma dezena espalhada principalmente pela região sudeste do País, tanto na cidade de São Paulo, quanto em Londrina, Maringá etc. Curiosamente, ao contrário do que se verificava nos anos setenta, na cidade do Rio de Janeiro a demanda por criação destes cursos parece não ter atraído a atenção das diversas universidades aí baseadas.

Contudo, os perfis dos cursos não caminham na mesma direção, observando-se nitidamente a tendência em torná-los “mais práticos". Por exemplo, o curso da Fundação Lusíada de SantosSP enfatiza o comércio portuário; a Universidade São Marcos, a gestão em negócios, enquanto o comércio exterior se constitui no elemento forte da Universidade Estácio de Sá; a PUC/SP e a Universidade de Brasília preocupam-se com uma formação mais acadêmica, centrada em Ciência Política, ainda que não descurem da História, do Direito e da Economia (principalmente no caso da instituição paulista, que privilegia uma forte integração interdisciplinar); a PUC/MG embora desejasse priorizar todas as áreas, mostra através de sua grade curricular a preferência pelo pragmatismo, o mesmo se verificando no caso da UNISUL, enquanto a UNIVALI apresenta um currículo bem equilibrado.
Em virtude de serem novos, com dois ou três anos, a demanda tem variado nas universidades mais "periféricas" em torno de dois candidatos por vaga, ao passo que na PUC/SP (cujo curso foi criado em 1995) os dados do vestibular de 1997 indicam a elevada procura pela carreira, com cerca de dezoito candidatos concorrendo a cada vaga oferecida, ficando sempre entre os três mais disputados da instituição. Neste último caso, a universidade reforçou significativamente seu quadro docente, contratando profissionais de reconhecida competência, como Oliveiros S. Ferreira e convidando outros como professores visitantes, como por exemplo Tullo Vigevani.

Ainda que o quadro seja positivo, de um lado, verifica-se, por outro, fato preocupante, qual seja, a não existência de recursos humanos suficientes na maioria dessas instituições, e que possam cumprir com eficácia tal tarefa. Assim, ocorre uma defasagem bastante acentuada entre a proposta de programa e o próprio domínio do assunto pelos docentes (e sua titulação), a ser desenvolvido durante o curso. Outro dado ainda a ser considerado é que, apesar de ter a rubrica "Relações Internacionais", a preocupação fundamental das entidades, como se mencionou anteriormente, é com o aspecto prático do curso, direcionando-o quase que exclusivamente para o comércio exterior.

No cômputo geral, contudo, o momento é altamente favorável se comparado com o clima existente há duas décadas. O número de eventos, por exemplo, é muito elevado, abordando aspectos os mais variados, promovendo-se inúmeros seminários internacionais, inclusive de alunos, como o realizado em setembro de 1997 em São Paulo com o $3^{\circ}$ Encontro de Estudantes e Graduados de Relações Internacionais do Cone Sul, sendo que o V Encontro será novamente no Brasil, no Distrito Federal, de 8 a 12 de outubro de 1999. Os estudantes criaram, ainda, a Federação Nacional dos Estudantes de Relações Internacionais (FENERI), como resultado dos Encontros Nacionais de Estudantes de Relações Internacionais (ENERI), que neste ano realizou a sua IV versão no Rio de Janeiro de 22 a 25 de abril. Outro grande evento estudantil diz respeito à simulação do modelo da ONU (Americas Model United Nations (AMUN 98)), com participação de alunos de universidades brasileiras e do exterior, sendo realizado em Brasília de 31 de março a 4 de abril 
de 1998. A nova edição da AMUN foi novamente no Distrito Federal em março de 1999.

O número de projetos de pesquisa sobre os mais variados temas das Relações Internacionais apresentados às entidades de fomento também são expressivos. De trinta solicitações feitas à Coordenadoria de Aperfeiçoamento de Pessoal de Ensino Superior (CAPES) em 1997, dez dessas, contempladas com recursos da entidade, diziam respeito a este campo de estudos, conforme quadro demonstrativo apresentado pelo professor José Flávio S. Saraiva no seminário onde este texto foi originalmente discutido.

Face, então, ao processo de integração regional, da estabilidade econômica e do processo de globalização, entre outros, o interesse tem crescido verticalmente, notado pelo número de faculdades criadas em período muito curto. Instala-se um clima de euforia que pode, contudo, ser frustrado pela qualidade oferecida, se as instituições diretamente envolvidas não tiverem o cuidado de suprir, de maneira adequada, as necessidades com pessoal suficientemente habilitado para que os cursos funcionem a contento e com um mínimo de qualidade.

A criação do CEBRI (Centro Brasileiro de Relações Internacionais), presidido pelo embaixador Baena Soares, e com a participação do atual chanceler Luís Felipe Lampréia e da professora Aspásia de Camargo, tem mostrado a importância adquirida pelos temas internacionais em escala cada vez mais ampla. Mesmo na UNICAMP, em 1993, se redigiu um documento propondo a criação de um Centro de Altos Estudos Internacionais (em moldes bem diferentes do Instituto de Estudos Avançados da USP), que seria composto por ex-chanceleres e figuras de projeção acadêmica nacional. O documento, contudo, não passou por qualquer discussão no âmbito do Instituto de Filosofia e Ciências Humanas (onde foi elaborado por iniciativa de apenas um docente), ou do Departamento de Ciência Política, o maior interessado no assunto, e sem qualquer consulta aos professores que trabalham na área. Referido projeto, entretanto, não seguiu avante.

Quanto à maior integração entre os profissionais que trabalham em Relações Internacionais verificam-se divergências bastante acentuadas. Por exemplo, na Universidade de São Paulo coexistem dois núcleos coordenados por docentes de um mesmo departamento, enquanto o Progra- ma de Pós-graduação em Integração na América Latina (PROLAM) também se localiza a poucos metros da Faculdade de Filosofia, Letras e Ciências Humanas; isto tudo faz com que os esforços acabem sendo multiplicados, independentemente da alta qualidade dos coordenadores e pesquisadores envolvidos naquelas instâncias.

O surgimento de pesquisadores jovens também é outro sinal animador, muitos deles realizando mestrado e doutorado, principalmente na USP, na PUC/RJ e na UnB. Outros, mais avançados, mas igualmente jovens, com boa formação acadêmica, têm reforçado os diversos departamentos, como podemos lembrar através de Mônica Herz, Letícia Pinheiro e Paulo Wrobel (IRI da PUC/RJ), ou Antônio Jorge R. da Rocha, Alcides Costa Vaz e Cristina Yumie Inoue (UnB), Alexandra Mello e Silva (CPDOC da FGV/RJ). Áreas importantes, ainda não preenchidas, aos poucos (ainda que muito morosamente) têm sido procuradas, com pesquisadores encaminhando seus trabalhos para assuntos como o Japão, e tendo realizado estágios ou fazendo os próprios cursos em universidades nipônicas, como ocorreu com Alexandre Ratsuo Uehara e Neide Sati Ishioka, de São Paulo, e Márcia Lissa Aida, graduada em Relações Internacionais pela UnB. Esta região do Pacífico inclusive já se consolidou como tema de investigação através de pesquisadores experimentados, como Henrique Altemani de Oliveira e Gilson Schwarts, entre outros, reunidos no Grupo de Estudos sobre a Bacia do Pacífico.

O fácil acesso às publicações internacionais também tem sido um instrumento útil no fortalecimento da área, bem como o acesso às informações via Internet, disponível nas universidades nacionais. Este último recurso, utilizado por todos, tem favorecido o aumento de interesse em Relações Internacionais, repercutindo na solidificação cada vez maior da área no País. A PUC de Minas Gerais mantém inclusive um site onde existem inúmeras informações sobre o Mercosul (Boletim Mercosul nas Universidades), formando uma rede com a maior parte das instituições de ensino do País que têm, entre suas preocupações, o estudo das Relações Internacionais. A publicação regular de bibliografias e de material de imprensa de vários países sobre o assunto tem igualmente facilitado a pesquisa que se processa de maneira mais veloz e cujos serviços podem ser acessados tanto pelo Centro de Documentação do Instituto de Relações Internacionais (IRI/PUC) ou pelas publicações do 
Centro Brasileiro de Documentação e Estudos da Bacia do Prata (CEDEP), da Universidade Federal do Rio Grande do Sul, ou via Ministério das Relações Exteriores. No Rio de Janeiro existe, também, o Programa de Estudos Europeus da Universidade Federal do Rio de Janeiro (dirigido por Franklin Trein).

Os convênios firmados pelas universidades também têm ajudado os alunos, como no caso da PUC/SP que, ao assinar acordo com a Universidade de Varsóvia, tem não só intercambiado professores, mas também levado dezenas de estudantes em viagens de estudos, principalmente ao Leste europeu em junho/julho de cada ano.

\section{CONCLUSÃO}

Como observações finais, pode-se dizer que o final da década de noventa vive momentos extremamente favoráveis ao aumento de interesse nas Relações Internacionais, tanto pelo meio acadêmico, quanto pelos setores políticos e econômicos.

Especificamente no Brasil, este interesse significa que a área continuará avançando face a alguns fatores que têm marcado, inclusive, o desenvolvimento político e econômico nacional. Ou seja, o crescimento da área de Relações Internacionais, academicamente, se dá à medida que o País se projeta no cenário internacional. Quanto mais espaços o País tiver, os estudos também sofrerão aumento diretamente proporcional, inclusive criandose instituições no exterior voltados ao estudo da realidade brasileira, como por exemplo, o Centro de Estudos Brasileiros da Universidade de Oxford.

O número de cursos de graduação também tende a aumentar face ao processo de integração, ainda que a direção imprimida a esses cursos seja no sentido de torná-los cada vez "mais práticos", propiciando ao aluno, principalmente, realizar negócios no âmbito regional e no mundo globalizado. O sucesso da área dependerá, entretanto, fundamentalmente, das condições oferecidas pelos cursos, tanto em termos de qualidade do corpo docente, quanto dos currículos.

Da mesma maneira que se verifica o crescimento da área, alguns problemas também demorarão certo tempo para serem resolvidos a contento. Por exemplo, o interesse no estudo das Relações Internacionais no Brasil está dirigido com grande intensidade para problemas relacionados ao funcionamento do Mercosul. Isso não é de se estranhar. A área de Relações Internacionais normalmente percorre os mesmos caminhos seguidos pelo desenvolvimento do País. Primeiramente ocorre o interesse pela atuação do País no nível continental, estudando-se as relações bilaterais e regionais com os Estados vizinhos. Só depois se começam a formular estudos analisando países que têm poder no cenário internacional, ao mesmo tempo que também se dedica algum tempo a temas contemporâneos. Somente após ter atingido certo estágio, é que os pesquisadores começam a dedicar mais espaço a estudos mais amplos e ambiciosos, fazendo análises mais consistentes sobre o sistema internacional de maneira global. Por isso, apenas agora é que surgiu o excelente livro coordenado por José Flávio Sombra Saraiva, contando com textos também de Amado Luiz Cervo, Paulo Roberto de Almeida e Wolgang Dopcke, todos da Universidade de Brasília, atrevendo-se a fazer obra de grande alcance. Da mesma forma, recentemente foi publicado o importante livro de Ricardo Seitenfus sobre as organizações internacionais (ver SARAIVA, 1997; cf., também, SEITENFUS, 1997).

Por outro lado, o momento propício indica que as demais áreas de interesse vão aos poucos sendo preenchidas, embora não com a velocidade desejada. Pode-se, ainda, perceber que as Relações Internacionais, no País, têm-se preocupado, em primeiro lugar, com aspectos históricos e políticos e, posteriormente, com aspectos econômicos e culturais. As variáveis militares sempre foram relegadas a plano secundário, a não ser com relação ao âmbito regional, como se observa no caso da Bacia do Prata. Destarte, assuntos como a segurança internacional têm ainda sido grandemente negligenciados, não recebendo atenção a não ser por parte de poucos pesquisadores, entre os quais aqueles diretamente ligados a setores de segurança do País, como bem chama sublinha Thomas Guedes da Costa da Universidade de Brasília (cf. COSTA, 1998).

Apesar dessas deficiências, pode-se afirmar que a área de Relações Internacionais no País encontra-se consolidada. Tanto os autores mais experimentados, quanto os mais jovens, têm-se dedicado com afinco e utilizado todo o instrumental teórico ao seu dispor, bem como as informações instantâneas obtidas através da informática.

Por último, seria interessante realizar um mapeamento o mais completo possível para se 
localizar os egressos dos cursos de Relações Internacionais, detectando quais os seus interesses e locais de trabalho, bem como as atividades ora exercidas, com a finalidade de se poder atender, realisticamente, a demanda desses futuros profissionais.

Recebido para publicação em fevereiro de 1999.

Shiguenoli Miyamoto (shigmag@ @ol.com.br) é Doutor em Ciência Política pela Universidade de São Paulo (USP) e Professor Livre Docente do Departamento de Ciência Política da Universidade Estadual de Campinas (UNICAMP).

\section{REFERÊNCIAS BIBLIOGRÁFICAS}

ALMEIDA, P. R. de. 1993. Revistas brasileiras de política internacional : um balanço de quatro décadas. Política Externa, São Paulo, vol. 2, n. 1, p. 162-169, jun./ago.

ARANGUREN, J. O e SCHELHOM, T. 1978. Un siglo de política exterior argentina. Buenos Aires : FLACSO.

ARAUJO CASTRO, J. A. 1972. O congelamento do poder mundial. Revista Brasileira de Estudos Políticos, Belo Horizonte, n. 33, p. 730 , jan.

BARROS, A. 1985. El estúdio de las relaciones internacionales en Brasil. In: PERINA, Ruben M. (comp.). El estúdio de las relaciones internacionales en América Latina y el Caribe. Buenos Aires : Grupo Editor Latinoamericano.

BETIOL, L. 1983. Itaipu : modelo avançado de cooperação internacional na Bacia do Prata. Rio de Janeiro : Editora da Fundação Getúlio Vargas.

BRASIL. Câmara Federal. 1975. A nova ordem mundial. Brasília : Seção de Publicações da Câmara Federal.

BRASIL. Câmara Federal. 1977. Valores e rumos do mundo ocidental. Brasília : Seção de Publicações da Câmara Federal.

CAMILION, O. 1973. Relaciones argentinobrasileñas. Estratégia, Buenos Aires, n. 21, p. 43-48, mar./abr.

CASTRO, T. de. 1976. Rumo à Antártica. São Paulo : Livraria Freitas Bastos.

CAUBET, C. 1991. As grandes manobras de Itaipu. São Paulo : Acadêmica.
CERVO, A. L. e BUENO, C. 1992. História da política exterior do Brasil. São Paulo : Ática.

CHEIBUB, Z. B. e LIMA, M. R. S. de. 1983. Relações internacionais e política externa brasileira : debate intelectual e produção acadêmica. Rio de Janeiro : IUPERJ. Mimeo.

CHEIBUB, Z. B. 1981. Bibliografia brasileira de relações internacionais e política externa. Rio de Janeiro : IUPERJ. Mimeo.

COSTA, T. G. da. 1998. Falta atenção aos temas de segurança internacional. Carta Internacional da USP, São Paulo, VI, vol. 59, n. 13, jan.

COUTO E SILVA, G. do. 1967. Geopolítica do Brasil. $2^{\mathrm{a}}$ ed. Rio de Janeiro : Livraria José Olympio Ed.

FONSECA JR., G. 1989. Estudos sobre política externa no Brasil : os tempos recentes (19501980). In: FONSECA JR., G. e LEÃO, V. C. (orgs.). Temas de política externa brasileira. Brasília : Fundação Alexandre de Gusmão/IPRI/ Ática.

FORJAZ, C. 1997. A emergência da Ciência Política acadêmica no Brasil : aspectos institucionais. Revista Brasileira de Ciências Sociais, São Paulo, vol. 12, n. 35, p. 101-120, out.

GRAEL, Cel. D. de. 1985. Aventura, corrupção e terrorismo : à sombra da impunidade. Petrópolis : Vozes.

IANNI, O. 1974. Imperialismo na América Latina. Rio de Janeiro : Civilização Brasileira.

LAMOUNIER, B. e CARDOSO, F. H. 1978. A bibliografia de Ciência Política sobre o Brasil : 1949-1974. Dados, Rio de Janeiro, n. 18, p. 03-32. 
LIMA, M. R. S. de e MOURA, G. 1981. BrasilArgentina : uma bibliografia comentada. Revista Brasileira de Política Internacional, Rio de Janeiro, XXIV, (93-96), p. 163-184.

LIMA, M. R. S. de e MOURA, G. 1982. Relações internacionais e política externa brasileira : uma resenha bibliográfica. BIB/ANPOCS, Rio de Janeiro, n. 13, p. 5-36, $1^{\circ}$ semestre.

LIMA, M. R. S. de. 1977. As fontes institucionais para a pesquisa em relações internacionais no Brasil. Texto apresentado ao seminário Perspectivas para o desenvolvimento de estudos comparativos latino-americanos e Relações Internacionais. Nova Friburgo, 2-3 de dezembro. Mimeo.

MARINI, R. M. 1974. Brazilian Subimperialism. Montlhy Review, New York, vol. 23, n. 9, p. 14-24, feb.

MARTINS, C. E. 1975. Evolução da política externa brasileira na década 64/74. Estudos Cebrap, São Paulo, n. 12, p. 53-98, abr./jun.

MEDEIROS, A. P. C. de. 1982. As relações internacionais como área de estudo na América Latina. Revista Brasileira de Estudos Políticos, Belo Horizonte, n. 55, p. 65-88, jul.

MEIRA MATTOS, C. de. 1983. O pensamento estratégico brasileiro : projeções das influências da nossa continentalidade. Política e Estratégia, São Paulo, vol. 1, n. 1, p. 177-185, out./ dez.

MEIRA MATTOS, C. de. 1975. Brasil : geopolitica e destino. Rio de Janeiro : Biblioteca do Exército Editora.

MENEZES, E. de. 1972. Antártica, interesses internacionais. Rio de Janeiro : ESG.

MIRROW, K. 1977. A ditadura dos cartéis. Rio de Janeiro : Civilização Brasileira.

MIYAMOTO, S. 1984. Notas sobre o estudo das Relações Internacionais no Brasil. Série Relações Internacionais, n. 3, UNESP, Campus de Marília (SP).

MIYAMOTO, S. 1981. Os estudos geopolíticos no Brasil : uma contribuição para sua avaliação.
Perspectiva, São Paulo, UNESP n. 4, p. 7592.

POMER, L. 1968. Guerra del Paraguay : gran negócio. Buenos Aires : Caldén.

RATTNER, H. (org.). 1978. A crise da ordem mundial. São Paulo : Símbolo.

SARAIVA, J. F. S. 1997. História das relações internacionais : o objeto de estudo e a revolução do conhecimento. In: SARAIVA, J. F. S. (org.) Relações internacionais contemporâneas : da construção do mundo liberal à globalização, de 1815 a nossos dias. Brasília : Paralelo 15.

SARAVIA, S. de A. 1981. Bibliografia selecionada sobre las relaciones argentino-brasileñas. Revista Brasileira de Política Internacional, Rio de Janeiro, XXIV, n. 93/96, p. 185-188.

SCHILLING, P. 1981. A geopolítica do general Golbery e a diplomacia do Itamaraty. São Paulo : Global.

SCHILLING, P. 1974. Brasil va a la guerra. Buenos Aires: Schapire.

SCHOOYANS, M. 1973. Déstin du Brésil. Gembloux : Duculot.

SEITENFUS, R. 1997. Manual das organizações internacionais. Porto Alegre : Livraria do Advogado Editora.

SOARES, A. T. 1973. História da formação das fronteiras do Brasil. 3a. ed. Rio de Janeiro : Biblioteca do Exército Editora.

STEPAN, A. 1974. Los militares y la politica en Brasil. Buenos Aires : Amorrortu.

TAMBS, L. 1970. Latin American Geopolitics : a Basic Bibliography. Revista Geográfica, Rio de Janeiro, n. 73, p. 71-105.

TRAVASSOS, M. 1945. Projeção continental do Brasil. 4a. ed. São Paulo : Companhia Editora Nacional.

VIEIRA, J. R. 1983. O ensino das Relações Internacionais no Brasil. Texto apresentado ao GRIPE no VII Encontro Anual da ANPOCS. Águas de São Pedro (SP), 26-28 de outubro. Mimeo. 
THE STUDY OF INTERNATIONAL RELATIONS IN BRAZIL: THE STATE OF THE ART

Shiguenoli Miyamoto (Universidade Estadual de Campinas)

This article reviews the study of International Relations in Brazil in two periods: before and after 1978. In the first period, we verify a small number of professionals and institutions devoted to these themes, whereas in the decade of the 1980's there was a notable increase in those numbers, specially with the creation of several undergratuate programs offering degrees in International Relations. The article also points to the difficulties faced by this area in the country, given intermissions in both teaching and research institutions devoted to the theme as well as in specialized publications.

KEY WORDS: International relations; Brazilian external politics; International Relations teaching institutions; International Relations periodicals. 
L’ÉTUDE DES RELATIONS INTERNATIONALES AU BRÉSIL: L’ETAT DE L’ART

Shiguenoli Miyamoto (Universidade Estadual de Campinas)

Cet article dresse le bilan de l'étude des Relations Internationales au Brésil au cours de deux périodes: avant et après 1978. Au cours de la première période, on peut noter un nombre réduit de professionels et d'institutions Qui se consacrent à cette thématique, alors qu'à partir de 1980 on remarque une amélioration significative, due notamment à la création de plusieurs cours Universitaires dans le domaine des Relations Internationales. L'article souligne également les difficultés rencontrées dans l'étude des Relations Internationales au Brésil, face aux intermittences des instituitions de renseignement, de recherche et des publications spécialisées.

MOTS-CLES: relations internationales; politique étrangère; instituitions de renseignement dans le domaine des relations internationales; périodiques. 